\title{
EL SUEÑO DE UN MUNDO FINITO. UNA APROXIMACIÓN AL PROBLEMA DE LA RELACIÓN MUNDO-LENGUAJE EN EL PENSAMIENTO DE NIETZSCHE
}

The Dream of a Finite World: An Approach to the Problem of the Relationship between Language and World in Nietzsche's Thought

\author{
Bruno Roldán
}

\begin{abstract}
RESUMEN: Nietzsche afirma en varias ocasiones que Aurora y La gaya ciencia constituían una introducción y un comentario de su Zaratustra, un comentario escrito antes que el propio texto. A través de la interpretación de algunos pasajes del capítulo «De los tres males» se examina la posibilidad de ampliar esta propuesta hermenéutica a un método de lectura que permita poner de manifiesto la coherencia interna del proyecto general de su filosofía. La elaboración de una concepción del mundo por medio del lenguaje y la crítica moral que se deriva de esta tarea constituyen dos aspectos estrechamente vinculados en su pensamiento.
\end{abstract}

Palabras clave: sueño - mundo - lenguaje - eterno retorno - ascetismo

ABSTRACT: Nietzsche says several times in his correspondence that Daybreak and The Gay Science were an introduction and a commentary of his Zarathustra, a commentary that he had written before the very text. By interpreting some passages in the chapter «On the three evils», we analyze the possibility of extending this hermeneutical proposal to a reading method that allows us to reveal the internal coherence of the overall project of his philosophy. Developing a conception of the world through language and moral criticism that results from this task are two aspects closely related in his thinking.

Keywords: Dream - World - Language - Eternal return - Asceticism

\section{EL COMENTARIO ESCRITO ANTES DEL TEXTO}

En una carta del 7 de abril de 1884 Nietzsche le revelaba a Overbeck un descubrimiento fundamental al que había llegado tras dar a luz la tercera parte de su Zaratustra: «Por lo demás, al releer Aurora y La gaya ciencia me he dado cuenta de que casi no hay en estas obras una sola línea que no pueda servir de introducción, preparación y comentario al citado Zaratustra. Es un hecho que he escrito el comentario antes del texto» ${ }^{1}$. No parece que se tratara de una ocurrencia ocasional, otros pasajes de su correspondencia nos confirman que Nietzsche tomaba muy en serio esta sugerencia de lectura.

Es interesante observar que esta idea se origina a raíz de un comentario que Heinrich Köselitz le había hecho tan solo un año antes con respecto a la primera

1. Carta a Franz Overbeck, 7 de abril de 1884, CO IV 504, eKGWB/BVN-1884, 504. 
parte del Zaratustra: «Todo su pensamiento y sus imágenes anteriores reciben ahora un envoltorio. A algunos les podía desconcertar la visión al descubierto de los engranajes que usted mostraba. Solo ahora es visible que se trataba de un organismo» ${ }^{2}$. Pocos días más tarde, el 23 de abril de 1883, Nietzsche le enviaba una respuesta confirmando lo acertado de su dictamen: «Su observación acerca de los 'engranajes' y el 'organismo' me parece correcta. Es curioso: he escrito el comentario antes que el texto»' . Era la primera vez que el filósofo hacía referencia a esta idea en sus cartas y posteriormente la reiteraría en varias ocasiones. Quizás sin pretenderlo, su estimado amigo veneciano pudo poner en marcha un ejercicio de auto interpretación mediante el cual Nietzsche fue capaz de percibir las líneas intertextuales que ligaban sus últimos escritos.

Desde los primeros días de febrero de 1883, Nietzsche venía anunciándole a Köselitz la inminente aparición de un nuevo libro, el Zaratustra, del que hablaba con evidente entusiasmo. Aún se hallaba alojado en el pequeño Albergo della Posta de la localidad de Rapallo, donde lo había redactado en apenas diez días del mes de enero poseído por un fulgurante arrebato de inspiración. En las cartas de aquellos días lo calificaba como el mejor de sus $\operatorname{libros}^{4} \mathrm{y}$ en general mostraba una gran confianza en la buena fortuna que acompañaría a su «hijo Zaratustra», pero en ocasiones dejaba traslucir ciertos temores en relación a la manera en que sería recibido ${ }^{5}$. Estas dudas terminaron por desembocar en una auténtica crisis. Nietzsche había enviado el manuscrito a su editor Schmeitzner el 14 de febrero con la pretensión de que se publicase con la misma rapidez con la que había sido concebido, pero un mes más tarde aún no había recibido siquiera las pruebas de imprenta. Apesadumbrado por esta situación, tal como se pone de manifiesto en una carta enviada a Overbeck, Nietzsche comenzó entonces a replantearse el verdadero valor de la obra: «Esto me trae a la mente mi última locura, quiero decir mi Zaratustra [...] siento curiosidad por saber si vale algo - personalmente este invierno soy incapaz de juzgar, y podría confundirme sobre los méritos y los defectos de la manera más grosera» ${ }^{6}$.

La publicación del libro tuvo que encarar varios obstáculos y no vio la luz hasta agosto de aquel año ${ }^{7}$, pero al menos las pruebas de imprenta estuvieron listas a principios de abril y, tal como era costumbre en aquella época, se las remitió a Köselitz para que procediese a su corrección. La reacción de su amigo y fiel colaborador fue extraordinariamente positiva y, tal como sugiere Janz, las cartas que en aquel momento le envió a Nietzsche pudieron serle de gran ayuda para superar su crisis de confianza ${ }^{8}$. Köselitz no escatimó en elogios a la hora de evaluar el nuevo escrito: «El magnífico giro de su espíritu, la fuerza de su lenguaje, la abundancia de invención hasta en los más pequeños detalles, el fervor y la majestad de su sentimiento,

2. Carta de Heinrich Köselitz, 17 de abril de 1883, KGB III/2 189, p. 367.

3. Carta a Heinrich Köselitz, 23 de abril de 1883, CO IV 405, eKGWB/BVN-1883, 405.

4. Cf. carta a Heinrich Köselitz, 1 de febrero de 1883, CO IV 370, eKGWB/BVN-1883, 370. Cf. también la carta a Overbeck del mismo día, CO IV 372, eKGWB/BVN-1883, 372.

5. Cf. las cartas a Köselitz y Overbeck del 1 de febrero y primeros de abril de 1883, CO IV 370 y 398, eKGWB/BVN-1883, 370 y 398.

6. Carta a Franz Overbeck, 22 de marzo de 1883, CO IV 393, eKGWB/BVN-1883, 393.

7. Cf. Carta a Heinrich Köselitz del 1 de julio de 1883, CO IV 428, eKGWB/BVN-1883, 428. p. 152.

8. Cf. C. P. Janz, Friedrich Nietzsche 3. Los diez años del filósofo errante, Madrid: Alianza, 1985, 
me maravillan, me emocionan, hacen que todavía me estremezca, hasta donde da de sí mi capacidad» ${ }^{9}$. El efecto tonificante de la positiva crítica de Köselitz se deja apreciar con claridad en la respuesta que Nietzsche le envía el 6 de abril: «Al leer su última carta he sentido un escalofrío. Suponiendo que usted tenga razón ¿entonces mi vida no sería un fracaso? ¿Y menos que nunca ahora cuando estaba más convencido de ello? [...] Quizá no haya experimentado nunca una alegría tan grande en mi vida como cuando he recibido su carta» ${ }^{10}$.

En todo caso, cabe percibir ciertas disonancias en la comunicación en las que es preciso reparar. Köselitz enfatizaba demasiado, y en un sentido plenamente literal, el carácter sagrado del texto que Nietzsche en alguna ocasión había calificado como un «quinto 'Evangelio'»"1 1 . En su carta del 2 de abril Köselitz afirmaba que «a este libro hay que desearle la difusión de la Biblia, su visión canónica, su comentario» ${ }^{12}$ y ante la pregunta de Nietzsche sobre la manera en que cabría clasificar propiamente al Zaratustra, Köselitz no parecía albergar ninguna duda, su lugar estaba «entre los 'escritos sagrados' ${ }^{13}$; no solo era un libro equiparable a la Biblia, sino que también podía ser puesto en relación con las enseñanzas budistas ${ }^{14}$. Nietzsche, por el contrario, tenía una visión bien distinta del carácter sacro de su escrito. Solo a condición de asumir con ello un distanciamiento irónico era posible otorgarle el calificativo de «libro sagrado», pues en modo alguno se trataba de un escrito piadoso: «Es una historia maravillosa: ihe desafiado a todas las religiones y he escrito un nuevo 'libro sagrado'! Y, dicho con toda seriedad, es un libro tan serio como cualquier otro libro sagrado, aunque introduzca la risa en la religión» ${ }^{15}$.

Así pues, el diálogo con Köselitz resultó sin duda fructífero para Nietzsche, si bien no parece que sus opiniones fueran en modo alguno convergentes. En sus cartas, Köselitz dejaba entrever que se sentía complacido por este nuevo "giro» (Wendung) espiritual hacia una posición mítico-religiosa y cuando le hablaba de la integración orgánica de los engranajes en el nuevo marco del Zaratustra parecía sugerir que sus obras anteriores habían quedado ampliamente superadas por el nuevo texto. Su verdadera función era la de ser simples piezas al servicio de una empresa de mayor alcance. Esa es la razón de que insinuara que sus libros precedentes dejarían de ser vistos como los extravíos positivistas que habían sembrado el «desconcierto» entre algunos de sus críticos, recibiendo así una especie de justificación ${ }^{16}$. Para Nietzsche, sin embargo, la imbricación entre el Zaratustra y sus

9. Carta de Heinrich Köselitz, 2 de abril de 1883, KGB III/2 184, pp. 359-360.

10. Carta a Heinrich Köselitz, 6 de abril de 1883, CO IV 401, eKGWB/BVN-1883, 401.

11. Carta a Ernst Schmeitzner, 13 de febrero de 1883, CO IV 375, eKGWB/BVN-1883, 375.

12. Carta de Heinrich Köselitz, 2 de abril de 1883, KGB III/2 184, p. 360.

13. Carta de Heinrich Köselitz, 6 de abril de 1883, KGB III/2 185, p. 361.

14. Cf. carta de Heinrich Köselitz, 17 de abril de 1883, KGB III/2 189, pp. 367-368. En posteriores ediciones del Zaratustra, como la que se publicó en 1910, Köselitz seguía corroborando en su introducción esta interpretación sagrada del texto que pudo jugar algún papel en la imagen de Nietzsche como nuevo mesías cultivada por el Archivo Nietzsche. (Cf. C. P. Janz, op. cit., pp. 175 176).

15. Carta a Malwida von Meysenbug, en torno al 20 de abril de 1883, CO IV 404, eKGWB/ BVN-1883, 404.

16. En cierto modo eso es lo que ocurrió con Erwin Rhode, uno de los más duros críticos con la dirección que había tomado el pensamiento de Nietzsche con la publicación de Humano, demasiado humano: «Tu 'Zaratustra' me ha producido, en todos los aspectos, una impresión más favorable que 
obras precedentes no solo era aún más estrecha de lo que suponía Köselitz, sino que además era de una naturaleza diferente. Al confirmar la observación sobre los «engranajes» y el «organismo» del Zaratustra, lo primero que añade Nietzsche es que ha escrito el comentario antes que el texto, es decir, sus textos anteriores no eran solo la introducción y la preparación para el Zaratustra, como añadirá posteriormente, sino también su necesaria ampliación exegética. El Zaratustra no anulaba o superaba los libros anteriores, sino que era su lógica continuación y precisaba de ellos para ser correctamente entendido.

Nietzsche no se olvidó de esta consideración y la mantuvo muy presente a lo largo del año posterior en el que salieron a la luz las dos partes siguientes del Zaratustra. La prueba más evidente de que seguía creyendo en este modo de acercarse a sus textos más recientes la tenemos en una carta dirigida a Resa von Schirnhofer de primeros de mayo de 1884, apenas unas semanas después de referir la misma opinión a Overbeck: «En cuanto a los temas para una bonita disertación, mi Aurora es una rica mina. Léala, por favor, y también La gaya ciencia - ambos libros son una introducción y un comentario de mi Zaratustra» ${ }^{17}$. Resa era una joven estudiante austríaca que se había trasladado a Zúrich para realizar un doctorado en filosofía. Por consejo de su «venerada y maternal amiga» Malwida ${ }^{18}$, la joven viajó a Niza entre los días 3 y 12 de abril para conocer a Nietzsche «quien debido al intenso trabajo en melancólica soledad necesitaba algo de aire fresco» ${ }^{19}$. En aquel encuentro, Resa debió hablarle a Nietzsche de su intención de doctorarse y este salió al paso ofreciéndose como tema para su disertación: «¿No podríamos destinar el invierno próximo a Niza y a la redacción de su disertación? —iConsidere esta posibilidad! $»^{20}$. En un momento en el que se incrementaron sus preocupaciones por la repercusión de su obra, pues consideraba que el Zaratustra, debido a su forma, era «accesible a cualquiera» y tendría, por tanto, un «efecto inmediato» ${ }^{21}$, Nietzsche bosquejó para Resa algunas pautas hermenéuticas para un estudio académico de su filosofía con las cuales podría sortearse el peligro de que el Zaratustra no se leyese con la debida seriedad y fuera arrojado «al montón de la 'literatura amena'» ${ }^{22}$. Le sugirió que en Aurora podían encontrarse definidos con mayor nitidez los contenidos temáticos para elaborar un estudio de su pensamiento y, de paso, le confió que tanto este libro como La gaya ciencia constituían una introducción y una ampliación explicativa de su Zaratustra. Resa optó finalmente por un tema completamente diferente, Comparación entre las doctrinas de Schelling y Spinoza (Zúrich, 1889), pero la

muchos de tus últimos escritos. iTe felicito por esta forma más libre de exponer tus puntos de vista que no es solo nueva en cuanto forma y se diferencia de tus anteriores cadenas de sentencias! [...] has empezado a encontrar tu propia forma. También tu lenguaje solo ahora encuentra sus tonos más plenos» (Carta de Erwin Rhode, 22 de diciembre de 1883, KGB III/2 218, p. 412).

17. Carta a Resa von Schirnhofer, primeros de mayo de 1884, CO IV 510, eKGWB/BVN1884,510 .

18. R. von Schirnhofer, «Vom Menschen Nietzsche»: Zeitschrift für philosophische Forschung 22/2 (abril- junio de 1968), p. 251.

19. Ibid.

20. Carta a Resa von Schirnhofer, primeros de mayo de 1884, CO IV 510, eKGWB/BVN$1884,510$.

21. Carta a Ernst Schmeitzner, 13 de febrero de 1883, CO IV 375, eKGWB/BVN-1883, 375.

22. Carta a Heinrich Köselitz, 6 de abril de 1883, CO IV 401, eKGWB/BVN-1883, 401. 
sugerencia de Nietzsche continúa vigente para que sea retomada por posteriores investigadores de su obra.

El presente artículo pretende ser un ejercicio de interpretación que toma como base esta sugerencia de Nietzsche como una propuesta hermenéutica viable capaz de aportar resultados concretos y la considera además como una estrategia ampliable a una visión general de la obra del filósofo. Es decir, trata de ejemplificar un método de lectura interno a los propios textos en el que se pongan de manifiesto los engranajes que articulan el proyecto general de su filosofía. Nietzsche no solo consideraba que los lazos con su obra anterior podían remontarse aún más atrás en el tiempo ${ }^{23}$, sino que pensaba además que con el Zaratustra había construido el «vestíbulo» de su filosofía y no habría de concederse descanso hasta haber logrado levantar el «edificio principal» ${ }^{24}$.

Partiendo de esta premisa, se considera la posibilidad de establecer una serie de movimientos de ida y vuelta en la lectura: del texto central, el Zaratustra, al comentario previo en Aurora y La gaya ciencia, para regresar después al vestíbulo de su filosofía y desde ahí echar una ojeada a ese edificio principal que, si bien quedó a medio construir, no muestra vacíos en términos de consistencia. También es legítimo invertir el orden de la mirada y comenzar con un vistazo a la fachada del edificio principal para introducirnos después en su vestíbulo y completar la imagen con un repaso del comentario. La idea fundamental es que en el Zaratustra se encontraba ya el germen de todo lo que habría de venir después y que sus textos anteriores pueden servir como herramienta para el análisis de un lenguaje literario que en ocasiones se presenta en este texto con extremada concisión. Para este ejercicio nos serviremos de algunos pasajes del capítulo «De los tres males» incluido en la tercera parte de la obra, pues se trata de un texto en el que se ve claramente la línea de continuidad con Aurora por su crítica moral, que tal como Nietzsche dirá posteriormente en Ecce Homo: «derrama su luz, su amor, su ternura nada más que sobre cosas malas, les devuelve otra vez 'el alma', la buena conciencia, el alto derecho y privilegio de existir $»^{25}$. No es otra la finalidad de este capítulo que trata de volver a "poner en la balanza» tres de las cosas que «han sido hasta ahora las más maldecidas» y sobre las que «se han dicho las peores calumnias y mentiras", "la voluptuosidad, la ambición de dominio y el egoísmo», para intentar «sopesarlas de un modo humanamente bueno» ${ }^{26}$.

Conecta además con La gaya ciencia por varias razones, primero porque en su primer libro Nietzsche continúa con esa revalorización del mal como un fenómeno de primer orden en la historia de la humanidad ${ }^{27}$. De haberse impuesto en toda su radicalidad alguna de las morales «insensatas y antinaturales» que han

23. «Todo está prometido en Schop<enhauer > como ed<ucador >; pero para llegar desde Hum $<$ ano $>$, demasiado hu<mano $>$ hasta el 'Superhombre' quedaba todavía un buen trecho que recorrer» (Carta a Heinrich Köselitz, 21 de abril de 1883, CO IV 405, eKGWB/BVN-1883,405).

24. «Ahora tengo que adentrarme poco a poco en una serie de disciplinas, porque he decidido emplear los próximos cinco años en la reelaboración de mi 'filosofía', para lo cual, con mi Zaratustra, he construido el vestíbulo» (Carta a Franz Overbeck, 7 de abril de 1884, CO IV 504, eKGWB/BVN1884, 504).

25. $\mathrm{EH}$ «Aurora», $\mathbb{S} 1, \mathrm{eKGWB} / \mathrm{EH}-\mathrm{M}-1$.

26. Za III «De los tres males», $\mathbb{\$} 1$, eKGWB/Za-III-Boese-1.

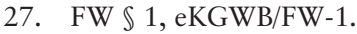


tratado de transformar la naturaleza del hombre, hace tiempo que «la humanidad habría sucumbido» ${ }^{28}$. En segundo lugar, porque en esta obra pueden observarse algunos de los trazos de la imagen nietzscheana del mundo que pueden servir para explicar algunos pasajes de este capítulo que de otro modo podrían pasar por referencias a algún tipo de simbolismo hermético. Y es que una de las características fundamentales de este texto es que en él se ponen en conexión tres esferas diferenciadas, comienza con una vía antimetafísica de conocimiento, el sueño, continúa con la imagen del mundo que este alumbra y culmina con una crítica moral, o más bien, una antimoral adecuada a esta nueva cosmovisión.

\section{2. «ASÍ ENCONTRÓ MI SUEÑO EL MUNDO...»}

El sueño con el que se inicia el capítulo «De los tres males» no apunta, como ocurre con otros sueños o visiones que aparecen en el transcurso de las narraciones de Zaratustra, a un sentido alegórico que sea preciso descifrar, sino que se presenta como una genuina vía de conocimiento: «En el sueño, en el último sueño matinal, yo me encontraba hoy sobre un promontorio, — más allá del mundo, sostenía una balanza y pesaba el mundo» ${ }^{29}$.

Para entender la verdadera función de este sueño, merece la pena echar un breve vistazo a la concepción general del sueño que hallamos en la obra de Nietzsche. El recurso a la actividad onírica como un fenómeno del que pueden extraerse algunas conclusiones de interés sobre la manera en que actúa el entendimiento en estado de vigilia constituye un tema recurrente en Nietzsche al menos desde Humano, demasiado humano. En el aforismo número trece titulado «Lógica del sueño", Nietzsche indagaba en la manera en la que en el sueño se buscan $a$ posteriori las causas de un determinado efecto, es decir, se atribuyen motivos inventados para explicar una determinada sensación producida por algún estímulo: «todo el mundo sabe por experiencia con qué rapidez el que sueña trenza en su sueño un sonido fuerte que llega hasta él, por ejemplo un retoque de campanas, un cañonazo» $\mathrm{y}$ «lo explica posteriormente de tal manera que cree vivir antes las circunstancias que producen ese sonido y luego el sonido mismo ${ }^{30}$. Nietzsche consideraba en este texto que este modo de razonar del hombre durante el sueño debió ser la manera en que lo hizo la humanidad durante «milenios también estando despierta: la primera causa que se le ocurría al espíritu para explicar algo que lo requiriera le bastaba y tenía valor de verdad» ${ }^{31}$. En el sueño continúa en activo ese estrato de la mentalidad de la humanidad primitiva sobre el que se desarrolló el pensamiento racional: «durante inmensos periodos de evolución hemos sido adiestrados perfectamente para esta manera fantástica y fácil de hallar explicación a la primera idea que nos venía a la cabeza» ${ }^{32}$.

En Crepúsculo de los ídolos, Nietzsche volverá a tratar esta «lógica del sueño» recurriendo a alguno de los ejemplos ya utilizados en Humano, demasiado

28. Ibid.

29. Za III «De los tres males», eKGWB/Za-III-Boese-1.

30. MA $\$ 13$, eKGWB/MA-13.

31. Ibid.

32. Ibid. 
bumano, como es el caso del «lejano disparo de cañón» al que se «le imputa retrospectivamente una causa (a menudo, toda una pequeña novela, en la que precisamente el que sueña es el personaje principal)» ${ }^{33}$, pero en esta ocasión el enfoque varía significativamente. Ya no se trata de un estadio superado en la evolución del pensamiento humano, sino del modelo que sirve para explicar el mecanismo general del «instinto causal»: «Las representaciones que fueron engendradas por una situación determinada son concebidas erróneamente como causa de ella. - De hecho cuando estamos despiertos actuamos también así. La mayoría de nuestros sentimientos generales [...] excitan nuestro instinto causal: queremos tener una razón de encontrarnos de este y de aquel modo, - de encontrarnos bien o encontrarnos mal» ${ }^{34}$. El recuerdo interviene de manera subrepticia proveyéndonos con las interpretaciones usuales con las que hemos explicado relaciones de causa y efecto similares en el pasado.

El fragmento sexto de esta sección, «Los cuatro grandes errores», concluye con la importante afirmación de que «El ámbito entero de la moral y la religión cae bajo este concepto de las causas imaginarias» ${ }^{35}$. En virtud de ciertas narraciones que quedaron automatizadas por la fuerza de los juegos de lenguaje de las formas de vida religiosas que durante siglos tuvieron un predominio cultural hegemónico, se aprendió a dar una explicación de los sentimientos agradables y desagradables yuxtaponiendo un esquema causal imaginario de orden moral o teológico. El malestar fisiológico era interpretado como un sentimiento de pecado o pecaminosidad, como castigo o expiación por una acción que no debía haberse realizado, mientras que el bienestar, "la buena conciencia", un estado fisiológico que a veces es tan semejante a una digestión feliz que se confunde con ella» se interpretaba como bienaventuranza, como un estado condicionado por la confianza en Dios: «La moral y la religión caen en su integridad bajo la psicología del error: en cada caso particular son confundidos la causa y el efecto; o la verdad es confundida con el efecto de lo creído como verdadero» ${ }^{36}$.

Existe una línea directa que enlaza esta sección de Crepúsculo de los ídolos con El Anticristo, donde Nietzsche explorará hasta sus últimas consecuencias esta cadena de argumentos. La moral y el cristianismo habían logrado imponer todo un mundo de causas y efectos imaginarios, hábilmente instrumentalizados por la figura del sacerdote, con los cuales no solo se daban motivos para explicar toda clase de estados internos, sino que se proyectaban las consecuencias que necesariamente habrían de derivarse de nuestros sentimientos, pensamientos, acciones y creencias. Como condición previa para que este mundo ficcional pudiera imponerse se requería de una atención obsesiva por el «mundo interior» (innere Welt) ${ }^{37}$, un

33. GD «Los cuatro grandes errores», $\mathbb{\$} 4$, eKGWB/GD-Irrthuemer-4.

34. Ibid.

35. GD «Los cuatro grandes errores», $\mathbb{6} 6$, eKGWB/GD-Irrthuemer-6.

36. Ibid.

37. El «mundo interior» del hombre religioso, afirma Nietzsche en otro pasaje de El Anticristo, es fruto de «epidemias nerviosas» y se asemeja al «'mundo interior' de los sobreexcitados y extenuados» (AC $\$ 51$, eKGWB/AC-51). Max Weber hablaba también de la «reflexión constante [...] como superación del status naturalis: los puritanos contemporáneos de Descartes tomaron su 'cogito ergo sum' con esta reinterpretación ética» (Max Weber, La ética protestante y el «espíritu» del capitalismo, Madrid: Alianza, 2012, p. 173). Pero había sido sobre todo la «inquietante doctrina del calvinismo» 
permanente rastreo de cada uno de los matices y variaciones del sentimiento y los estados mentales, mientras que el mundo externo quedaba reducido a un juego de sombras chinescas: «El concepto de culpa y de castigo, el entero 'orden moral del mundo', se han inventado contra la ciencia [...] El hombre no debe mirar hacia fuera, debe mirar dentro de sí: no debe mirar hacia las cosas con astucia y precaución, como alguien que aprende, no debe mirar en absoluto: debe sufrir...» ${ }^{38}$. Ya en el parágrafo quince de la obra, Nietzsche había expuesto con claridad esta idea sobre la que regresa con frecuencia a lo largo de todo el libro:

Ni la moral ni la religión tienen contacto, en el cristianismo, con punto alguno de la realidad. Causas puramente imaginarias ('Dios', 'alma', 'yo', 'espíritu', 'la voluntad libre', o también 'la no libre'); efectos puramente imaginarios ('pecado', 'redención', 'gracia', 'castigo', 'remisión de los pecados'). Un trato entre seres imaginarios ('Dios', 'espíritus', 'almas'); una ciencia natural imaginaria (antropocéntrica; completa ausencia de causas naturales); una psicología imaginaria (puros malentendidos acerca de sí mismo, interpretaciones de sentimientos generales agradables o desagradables, de los estados del nervus sympathicus, por ejemplo, con ayuda del lenguaje de signos de una idiosincrasia religioso-moral, - 'arrepentimiento', 'remordimiento de conciencia', 'tentación del demonio', 'la cercanía de Dios'); una teleología imaginaria ('el reino de Dios', 'el juicio final', 'la vida eterna') [...] todo aquel mundo de ficción tiene su raíz en el odio a lo natural (—ila realidad!- ), es expresión de un profundo descontento con lo real... ${ }^{39}$.

En este fragmento encontramos también una importante referencia al sueño. Habíamos visto que en su periodo de madurez, Nietzsche había dejado de ver la actividad onírica como un modo imperfecto de pensamiento en el que la humanidad se retrotrae a estadios anteriores de su evolución y había comenzado a considerarla como un modelo del que pueden extraerse algunos de los patrones de razonamiento que efectivamente usamos estando despiertos. Es cierto que en el sueño la imaginación somete a una reelaboración las experiencias realmente vividas, pero en cierto modo sus productos son superiores y más reales que el puro mundo ficcional de la teología: «Este puro mundo de ficción se diferencia, con gran desventaja suya, del mundo de los sueños por el hecho de que este último refleja la realidad, mientras que aquel falsea, desvalora, niega la realidad ${ }^{40}$. Así pues, si partiendo del sueño, como señalaba Nietzsche en el parágrafo cuarto de «Los cuatro grandes errores», puede descubrirse el adiestramiento en el instinto causal del hombre despierto, también hay una manera en la que el sueño puede mostrar una vía de adiestramiento para la desautomatización liberadora del mundo ficcional de la metafísica. Eso es lo que precisamente planteaba Nietzsche en el fragmento 193 de Más allá del bien y del mal:

Lo que vivimos en el sueño, suponiendo que lo vivamos a menudo, pertenece a fin de cuentas a la economía global de nuestra alma, igual que cualquier cosa 'realmente' vivida: gracias a ello somos más ricos o más pobres [...] y, finalmente, en pleno día, e

la que había introducido «ese impulso para un autocontrol constante y, en definitiva, para una reglamentación planificada de la propia vida» (ibid., p. 185).

38. AC $\$ 49, \mathrm{eKGWB} / \mathrm{AC}-49$

39. AC $\$ 15, \mathrm{eKGWB} / \mathrm{AC}-15$.

40. Ibid. 
incluso en los momentos más serenos de nuestro espíritu despierto, acabamos un poco tutelados por los hábitos de nuestros sueños. Suponiendo que alguien haya volado con frecuencia en sus sueños y, al final, tan pronto como empezara a soñar, se volviera consciente de una fuerza y de un arte de volar como de su privilegio, también como de su felicidad más propia y envidiada: alguien así, que cree poder realizar toda suerte de arcos y ángulos con el más silencioso de los impulsos, que conoce la sensación de cierta frivolidad divina, de un 'hacia arriba' sin tensión ni coacción, de un 'hacia abajo' sin condescendencia ni envilecimiento - isin pesadez - iCómo no iba a encontrar al hombre de tales experiencias y hábitos de sueño incluso en su vigilia, con otro color y significado la palabra 'felicidad'! 41 .

Este entrenamiento en el arte de la ligereza, que confirma el verdadero interés que tenía Nietzsche por la experimentación onírica, alude sin lugar a dudas a la experiencia de los sueños lúcidos, aquellos en los que el durmiente cobra consciencia de estar soñando y es capaz de realizar actos voluntarios, entre los cuales destaca como uno de los más comunes el acto de volar. En el sueño del capítulo «De los tres males», «el último sueño matinal», precisamente uno de los momentos más proclives a los sueños lúcidos, Zaratustra se encuentra elevado sobre un promontorio más allá del mundo y lo sostiene en una balanza. De ese modo sería posible desautomatizar las narraciones usuales que encadenan a la humanidad a un mundo lastrado por el espíritu de pesadez, pues tal como afirma Zaratustra en otro lugar aludiendo a una sentencia clásica de Solón: «Aquel que enseñe a volar a los hombres, ese habrá movido los mojones de todas las fronteras. Hará que todos los mojones salten por los aires y bautizará de nuevo a la tierra como - 'la liviana' ${ }^{42}$. En el sueño matinal de Zaratustra, el mundo se vuelve «sopesable para un buen pesador, sobrevolable para alas fuertes, adivinable para divinos cascanueces: así encontró mi sueño el mundo» ${ }^{43}$, "also fand mein Traum die Welt». Frente a la espectralización del mundo real establecida por la metafísica y la teología con ayuda de esa hiperestimulación de la conciencia revertida en mirada interior que deriva en un mundo ficcional que "falsea, desvalora, niega la realidad», el sueño de Zaratustra encuentra, recupera (finden) el mundo. Y no lo hace como una realidad execrable o atemorizante, sino "como si una manzana se ofreciese a mi mano, una madura manzana de oro, de piel aterciopelada, fresca y suave: - así se me ofrecía el mundo» ${ }^{44}$, un fruto deleitable ajeno a cualquier cálculo instrumental del valor y a su escisión dicotómica en valor de uso y valor de cambio. No es extraño, como hace notar Vivetta Vivarelli, que en medio de la atmósfera irreal de este sueño se intercalen imágenes que aluden, tal como veremos después, a un contexto científico. Vivarelli revela, por ejemplo, que en la imagen de la manzana se esconde una referencia a un pasaje de Emerson en el que resumía la ley de la gravedad de Newton: «la tierra en la que habitamos no es más que una gran manzana que cae de un árbol aún mayor ${ }^{45}$. No será la única referencia al mundo de objetos de la ciencia; el saber de las alturas de Zaratustra nos

41. JGB $\$ 193$, eKGWB/JGB-193.

42. Za III «Del espíritu de la pesadez» $\$ 2$, eKGWB/Za-III-Geist-2.

43. Za III «De los tres males», $\mathbb{\$} 1$, eKGWB/Za-III-Boese-1.

44. Ibid.

45. R. W. Emerson, Die Führung des Lebens, Leipzig: Steinacker, 1862, p. 213. Cf. V. Vivarelli, «Umkehr und Wiederkehr», en V. Gerhardt, Friedrich Nietzsche. Also sprach Zarathustra, Berlin: Akademie, 2012, pp. 256-257. 
advierte de que: «Es necesario aprender a apartar la mirada de sí para ver muchas cosas: - esa dureza la necesita todo aquel que escala montañas ${ }^{46}$.

\section{LA RIENTE Y DESPIERTA SABIDURÍA DEL DÍA QUE SE BURLA DE TODOS LOS «MUNDOS INFINITOS»}

Los sueños de conocimiento de Zaratustra son impacientes y persiguen su presa «cual halcones de cetrería» ${ }^{47}$, pero en esta ocasión algún conocimiento asimilado al caudal de su sabiduría consciente le permite demorarse con «paciencia y tiempo para pesar el mundo»: «¿Acaso le alentaba secretamente a ello mi sabiduría, mi riente y despierta sabiduría del día, que se burla de todos los 'mundos infinitos'? Pues ella dice 'donde hay fuerza, allí también el número se convierte en dueño: pues tiene más fuerza'»48.

¿A qué mundos infinitos (unendliche Welten) alude aquí Zaratustra? ¿Qué es lo que provoca su burla? Lo cierto es que algunas de las referencias que encontramos en este pasaje serían difícilmente interpretables sin recurrir al comentario previo de La gaya ciencia y si no se tuviese en cuenta que detrás de ellas se esconde una alusión a lo que constituye la "concepción fundamental» de todo el Zaratustra ${ }^{49}$, el pensamiento del eterno retorno, doctrina que aparece mencionada de manera explícita en pocas ocasiones, pero que permanece como una presencia latente prácticamente a lo largo de toda la obra.

En al menos dos de las fuentes relacionadas con esta teoría cosmológica se hace la defensa de una infinitud espacial que tendría como consecuencia una pluralidad infinita de mundos. Una de ellas es la obra que Louis-Auguste Blanqui escribió desde la cárcel, La eternidad a través de los astros. No tenemos constancia de que Nietzsche llegara a leer esta obra, el único indicio que encontramos de que al menos la conocía es que aparece mencionada en un cuaderno redactado durante el otoño de 1883, N VI 6: «A. Blanqui, l'eternité par les astres, París, $1872 »^{50}$. Este cuaderno contenía sobre todo anotaciones para la tercera parte del Zaratustra, de manera que no se puede descartar del todo que detrás de esa expresión entrecomillada, «mundos infinitos», estuvieran también presentes las tesis de Blanqui. Sin embargo, en el cuaderno M III 1 redactado entre la primavera y el otoño de 1881 en el que quedaron registradas las primeras anotaciones sobre el eterno retorno tras la súbita inspiración ante la roca de Surlej, así como en el grueso de apuntes para una fundamentación teórica de la doctrina, no encontramos la más mínima huella de esta obra.

Blanqui hacía una defensa de una cosmología cíclica en la que se presuponía la existencia de un tiempo infinito que tendría como necesaria consecuencia la eterna repetición de cada acontecimiento. En algunos momentos, tal como ya señalaba Montinari ${ }^{51}$, su exposición recuerda vivamente a la que hace Nietzsche

46. Za III, «El caminante», eKGWB/Za-III-Wanderer.

47. Za III «De los tres males», $\mathbb{S} 1$, eKGWB/Za-III-Boese-1.

48. Ibid.

49. $\mathrm{EH}$ «Así habló Zaratustra», $\mathbb{~ 1 , ~ e K G W B / E H - Z A - 1 . ~}$

50. FP III 17 [73], eKGWB/NF-1883,17[73].

51. Cf. M. Montinari, Lo que dijo Nietzsche, Barcelona: Salamandra, 2003, pp. 110-111. 
por boca del demonio en el fragmento 341 de La gaya ciencia $^{52}$. Sin embargo, además de un tiempo infinito, Blanqui postulaba una infinitud espacial, presupuesto que le bastaba para justificar la existencia de lo que en siglo Xx será conocido como multiverso. No solo habría de darse una infinita repetición de los mismos acontecimientos, la infinitud del espacio aseguraba además la proliferación infinita de todas las variantes posibles de cada evento, que se ramificarían en mundos diferentes a cada instante: «la fatalidad no hace pie en el infinito, que tampoco conoce alternativa y tiene lugar para todo. Una Tierra existe donde el hombre sigue la ruta desdeñada en la otra por el sosias. Su existencia se desdobla, un globo para cada una, luego se bifurca una segunda, una tercera, miles de veces. Posee así sosias completos y variantes innumerables de sosias, que multiplican y representan siempre a su persona, pero que solo obtienen jirones de su destino» ${ }^{53}$.

Más probable parece, sin embargo, que esta alusión hiciera referencia a otra obra en la que se proponía una tesis con rasgos similares, el tratado de Johann Gustav Vogt, La fuerza. Una concepción del mundo realista y monista. En este caso sí tenemos sobrada constancia de que Nietzsche la había estudiado con notable atención, pueden hallarse diversas referencias en el cuaderno M III 1 y volvió de nuevo a ella en 1882 y en 1883, antes de publicar la tercera parte del Zaratustra ${ }^{54}$. El modelo cosmológico de Vogt se regía por una premisa básica, la existencia de una única fuerza en todo el universo que se distribuye en una serie infinita de «centros de fuerza» (Kraftcentren) cuya actividad fundamental se traduce en un movimiento de contracción: «La forma efectiva mecánica fundamental de la fuerza, eternamente inalterable y homogénea, es la contracción, o conforme a una representación más material, la condensación ${ }^{55}$. Los centros de fuerza entran en contacto a través de una esfera de acción (Wirkungssphäre) que hace posible un estado de continuidad absoluta donde no hay lugar para el vacío. Al momento positivo del movimiento fundamental de contracción le sucede un momento negativo de expansión y Vogt consideraba que todos los fenómenos físicos podían explicarse por una alternancia entre ambos polos con un enérgico ritmo vibratorio. A escala cosmológica esto implicaba una constante oscilación energética en la que el agotamiento de unos mundos por la distensión o condensación extrema de los centros de fuerza debía originar como reacción el nacimiento de otros mundos en otro lugar por el proceso contrario: «el impulso de condensación, que conduce a nuestra zona del mundo a la inmovilización, despierta nuevos impulsos vitales en otras zonas del mundo. Un eterno proceso circular, un eterno ir y venir de mundos, y con ellos, de seres sintientes, pensantes y cognoscentes ${ }^{56}$.

Zaratustra se «burla de todos los 'mundos infinitos'» y Nietzsche había sometido a crítica esta versión de la hipótesis cíclica en dos fragmentos póstumos de $1881^{57}$.

52. Cf. L.-A. Blanqui, La eternidad a través de los astros, México: Siglo XXI, 2000, p. 58.

53. Ibid., p. 45.

54. Cf. FP II 11 [308, 311, 312, 313], eKGWB/NF-1881,11[308, 311, 312, 313]; FP III 2 [3], eKGWB/NF-1882,2[3] y FP III 24 [36], eKGWB/NF-1883,24[36].

55. J. G. Vogt, Die Kraft. Eine real-monistische Weltanschaunng, Leipzig: Haupt \& Tischler, 1878, p. 20.

56. Ibid., p. 655.

57. Cf. FP II 11 [311] y 11 [313], eKGWB/NF-1881,11[311] y 11 [313]. Sobre la discusión que Nietzsche establece con Vogt en estos fragmentos, cf. P. D’Iorio, «El eterno retorno: Génesis 
En uno de ellos puede leerse: «Suponiendo que hubiera una 'energía de contracción' homogénea en todos los centros de fuerza del universo, se pregunta entonces de dónde podría provenir siquiera la más mínima diversidad. En ese caso, el universo tendría que disolverse en innumerables círculos y esferas de existencia absolutamente iguales, y nosotros tendríamos, UNOS JUNTO A OTROS, innumerables mundos absolutamente iguales. ¿Es necesario que suponga algo así? ¿junto a la sucesión eterna de mundos iguales, la eterna simultaneidad? ${ }^{58}$.

Como hipótesis contraria a la idea de los mundos infinitos, la sabiduría despierta de Zaratustra defiende la limitación y distribución numérica de la fuerza: «Pues ella dice 'donde hay fuerza, allí también el número se convierte en dueño'». En este caso cabría ver una alusión a la teoría del científico dálmata Roger Josef Boscovich en la que la materia quedaba reducida a la acción de partículas simples puntuales carentes de parámetros físicos, cuyo comportamiento quedaba recogido en una única ley que describía en términos matemáticos su disposición a desplegar aceleraciones relativas en sus interacciones con otras partículas: «dos puntos de materia están sometidos a una disposición a aproximarse entre sí a ciertas distancias, y en el mismo grado a retroceder el uno del otro en otras distancias. Llamo a esta disposición 'fuerza'; en el primer caso la llamo 'atractiva', en el segundo 'repulsiva'; este término no denota el modo de acción, sino la propensión misma, cualquiera que sea su orden. La magnitud cambia cuando la distancia varía, y esto de acuerdo con una ley definida que puede ser representada por una curva geométrica o una fórmula algebraica» ${ }^{59}$.

Nietzsche, que consideraba a Boscovich, junto a la figura de Copérnico, «el adversario más grande y victorioso de la apariencia visible» ${ }^{60}$ por haberse opuesto a la existencia de los átomos materiales, había defendido además en un fragmento de La gaya ciencia que las matemáticas podían servir para «fijar [...] nuestra relación humana con las cosas. Las matemáticas son solo el medio del conocimiento universal y último del hombre» ${ }^{61}$.

Otros fragmentos del comentario previo, como el número 109 nos ofrecen algunas claves de la imagen del mundo que está detrás de este pasaje del Zaratustra en el que pueden identificarse las huellas de diversas lecturas como la de Vogt: «Guardémonos de pensar que el mundo crea eternamente algo nuevo. No hay substancias eternamente duraderas; la materia es un error del mismo tipo que el dios de los eleatas" ${ }^{62}$. Se trata de un mundo finito que en el transcurso de una infinitud temporal da lugar a las mismas combinaciones de fuerzas y, por tanto, a los mismos eventos. No hay, sin embargo, ningún orden, ni causas finales, ni siquiera leyes que no sean una visión antropomórfica de un mundo, cuyo carácter es en realidad: «para toda la eternidad, caos, no en el sentido de que falte la necesidad, sino en el de que falta el orden, la articulación, la forma, la belleza, y

e interpretación», en J. Conill-Sancho y D. Sánchez Meca, Guía Comares de Nietzsche, Granada: Comares, 2014, pp. 157-163.

58. FP II 11 [311], eKGWB/NF-1881,11[311].

59. R. J. Boscovich, A Theory of Natural Philosophy, Chicago/London: Open Court, 1922, p. 39.

60. JGB $\$ 12, \mathrm{eKGWB} / \mathrm{JGB}-12$.

61. FW $\$ 246, \mathrm{eKGWB} / \mathrm{FW}-246$.

62. FW $\$ 109$, eKGWB/FW-109. 
como quieran llamarse todas nuestras estéticas categorías humanas» ${ }^{63}$. En otro aforismo de La gaya ciencia, Nietzsche vuelve a afirmarlo: «nosotros lo sabemos bien, el mundo en el que vivimos no es divino, es inmoral, 'inhumano', - lo hemos interpretado durante demasiado tiempo de modo falso y mendaz» ${ }^{64}$.

\section{CONCLUSIONES}

A pesar de todo, la visión de este mundo «inhumano» no provoca sentimiento alguno de inquietud, sino más bien al contrario: «Qué seguro contemplaba mi sueño este mundo finito, lo contemplaba no curioso, no indiscreto, no temeroso, no suplicante» ${ }^{65}$. De hecho, conlleva una transvaloración y al mismo tiempo una redefinición que permite humanizar las cosas más malvadas que existen. Si el mundo se había redimido: «iuna cosa humanamente buena era hoy para mí el mundo, al que tantas cosas malas se le atribuyen!», para proceder «durante el día como él, y seguirlo en lo mejor de él: quiero yo ahora poner en la balanza las tres cosas más malvadas que existen y sopesarlas de un modo humanamente bueno» ${ }^{66}$. Toda visión del mundo lleva consigo una serie de actos de habla directivos que indican la mejor manera de conducirse en él. El mundo del sueño de Zaratustra no está diseñado con líneas perfectas, sino que es un «árbol de amplio ramaje, de voluntad fuerte, torcido (gekrümmt) como para ofrecer respaldo e incluso escabel al cansado del camino: así se erguía el mundo sobre mi promontorio» ${ }^{67}$. Se trata de un árbol torcido en el que reposa sin violencia la enmarañada materia de la naturaleza humana. Por el contrario, fue el nihilismo antropológico heredero de la cosmovisión cristiana el que introdujo las pesadillas distópicas en la modernidad con el imperativo de enderezar la torcida materia del hombre. Kant, por ejemplo, decía en un escrito de 1784 que "con una madera tan retorcida (krummen Holze) como es el hombre no se puede conseguir nada completamente derecho» ${ }^{68}$. De manera similar a Mandeville o Adam Smith, Kant estimaba que los vicios privados podían ser útiles al buen desarrollo del colectivo al insertarse en un proceso de competencia y mutuo antagonismo con el que se limaban las asperezas de la ensortijada madera humana. Con ello se estaría siguiendo de manera inconsciente un plan teleológico proyectado por la naturaleza ${ }^{69}$. De no ser por la benéfica influencia de esta oposición, el individuo caería aplastado por el peso de sus propias inclinaciones: "como ocurre con los árboles del bosque que, al tratar de quitarse unos a otros aire y sol, se esfuerzan a buscarlos por encima de sí mismos y de ese modo crecen erguidos; mientras que aquellos otros que se dan en libertad y aislamiento, extienden sus ramas caprichosamente y sus troncos enanos se encorvan y retuercen ${ }^{70}$.

63. Ibid.

64. FW $\$ 346$, eKGWB/FW-346

65. Za III «De los tres males», $\mathbb{S} 1$, eKGWB/Za-III-Boese-1.

66. Ibid.

67. Za III «De los tres males», $\mathbb{S} 1$, eKGWB/Za-III-Boese-1.

68. «Idea de una historia universal en sentido cosmopolita» en E. Kant, Filosofía de la historia, México: FCE, 1994, p. 51.

69. Ibid., p. 40.

70. Ibid., p. 50 
El presupuesto para esta necesidad de mejorar lo humano se encontraba, por tanto, en una interpretación con reminiscencias gnósticas de la naturaleza y del mundo como algo imperfecto, algo que no le había salido del todo bien a su hacedor. En consecuencia, sus criaturas acusaban los peores vicios del contexto natural del que procedían: «iDemasiadas cosas le salieron mal a ese alfarero que no había aprendido del todo su oficio! Pero el hecho de que se vengase en sus vasijas y en sus criaturas porque le salieran mal a él - eso era un pecado contra el buen gusto» ${ }^{71}$. Es preciso recordar que Nietzsche se distanció abiertamente de cualquier proyecto de mejora de lo humano al comienzo de Ecce Homo: «Yo soy un discípulo del filósofo Dioniso, preferiría ser un sátiro antes que un santo [...] la última cosa que yo pretendería sería 'mejorar' a la humanidad. Yo no establezco ídolos nuevos, los viejos van a aprender lo que significa tener pies de barro. Derribar ídolos ('ídolos' es mi palabra para decir 'ideales') — eso sí forma ya parte de mi oficio» ${ }^{72}$. La moral no ha sido otra cosa que «un lecho de Procusto» ${ }^{73}$ y siempre que se ha pretendido mejorar lo humano mediante medidas disciplinarias como el monasterio, el producto ha sido el de «una caricatura de hombre [...] lleno de odio contra los impulsos que incitan a vivir, lleno de sospechas contra todo lo que continuaba siendo fuerte y feliz. En suma, un 'cristiano'... ${ }^{74}$.

La burguesía creía haber «sofocado el sagrado embeleso de la ilusión piadosa» en las "aguas heladas del cálculo egoísta» ${ }^{75}$, pero lo que había ocurrido en realidad podía sintetizarse con aquella sentencia de Sebastian Franck con la que Max Weber resumía el sentido de la Reforma: «Te crees que te has escapado del convento, pero ahora cada cual tiene que ser un monje durante toda su vida ${ }^{76}$. Al derribar los muros del monasterio, el mundo entero se había convertido en un convento regido por la férrea disciplina de la ascética intramundana. Era como si ese mal alfarero, enloquecido por la velocidad, hubiera pisado a fondo el pedal del torno de su taller de mundos, pero sus vasijas contrahechas ya nada podían saber de él, los mensajes acerca de su redención ya no llegaban, pues junto con los muros del monasterio se había derruido el altar de la oración. No obstante, permanecía vigente en ellos esa mirada interior agudizada por una autoconsciencia sobreexcitada, y atormentados por la visión de su arcilla mal cocida, seguían sin necesidad de un mentor externo la máxima dictada por la modulación del control. Una tarea entendida como un permanente aumento en su eficacia como trabajadores y como miembros funcionales del colectivo que en el contexto actual, tal como señalaba Deleuze, se distingue del moldeado de las antiguas sociedades disciplinarias porque constituye un proceso sin final: «En las sociedades disciplinarias siempre había que volver a empezar (terminada la escuela, empieza el cuartel, después de este viene la fábrica), mientras que en las sociedades de control nunca se termina nada: la empresa, la formación o el

71. Za IV «Jubilado», eKGWB/Za-IV-Dienst.

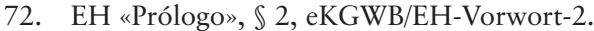

73. $\mathrm{M} \ 499$, eKGWB/M-499; GD «Incursiones de un intempestivo», $\mathbb{4} 43$, eKGWB/GD-Streifzuege-43.

74. GD «Los 'mejoradores' de la humanidad», $\mathbb{2}$, eKGWB/GD-Verbesserer-2.

75. K. Marx y F. Engels, Manifiesto comunista, Madrid: Alianza, 2001, p. 52.

76. «El despliegue de la mentalidad capitalista» en M. Weber, La ética protestante y el espíritu del capitalismo, Madrid: Akal, 1998, p. 331. 
servicio son los estados metaestables y coexistentes de una misma modulación, una especie de deformador universal $\gg^{77}$.

Si Max Weber pensaba que el ethos que impulsó la modernidad capitalista había terminado por desembarazarse de su sentido religioso, la tesis que podemos extraer de Nietzsche resulta mucho más radical. Como luego diría Walter Benjamin, el capitalismo no representaba en modo alguno un giro secular, sino más bien al contrario, se trataba del estadio religioso más extremo que se haya dado nunca. Una religión sin teología ni dogma, pero cuyo culto exige una práctica permanente que no sabe de interrupciones profanas. Se trata además de un insólito fenómeno religioso, puesto que no busca la expiación de sus acólitos, sino su eterna culpabilización ${ }^{78}$. Nietzsche avanzó ya esta consideración al señalar que la religión no había sucumbido con el acontecimiento de la muerte de Dios, es más, se las había arreglado muy bien para conservar incorrupto el cadáver del nihilismo europeo, cuya vigencia omnipotente se debe precisamente al hecho de que nunca hemos llegado a ser lo suficientemente ateos, jamás hemos alcanzado esa «segunda inocencia» que representaría una victoria definitiva sobre el espíritu ascético y nos liberaría de todo ese sentimiento de hallarse en deuda con una causa prima ${ }^{79}$. Para ello se requeriría de la capacidad de soñar mundos futuros a los que tal vez habría de sorprender el despertar de una nueva aurora, desautomatizar los juegos del lenguaje de las cosmovisiones vigentes y dar forma con palabras a mundos cuyo rendimiento performativo se adecúe mejor a nuevas formas de vida. Respetando «el pudor con el que la naturaleza se ha ocultado detrás de enigmas y multicolores incertezas ${ }^{80}$, es posible dar vida a interpretaciones que no pretendan un arreglo cosmético del mundo, sino una vivencia más plena e intensa del mismo ${ }^{81}$. Solo gracias a la «necedad» del habla sería posible llevar a cabo esta tarea que nos permitiría reconfortarnos en las cosas:

¿No se les han regalado acaso a las cosas nombres y sonidos para que el hombre se reconforte en las cosas? Una hermosa necedad es el hablar: al hablar, el hombre baila sobre todas las cosas.

¿Qué agradables son todo hablar y todas las mentiras de los sonidos! Con sonidos baila nuestro amor sobre arcoíris de todos los colores ${ }^{82}$.

77. «Post-Scriptum sobre las sociedades de control», en G. Deleuze, Conversaciones, Valencia: Pre-Textos, 2014, p. 280.

78. «Kapitalismus und Religion» en W. Benjamin, Gesammelte Schriften, vol. 6, Frankfurt am Main: Suhrkamp, 1991, pp. 100-103.

79. GM II, $\mathbb{S} 20, \mathrm{eKGWB} / \mathrm{GM}-\mathrm{II}-20$.

80. FW «Prólogo», $\mathbb{S} 4$, eKGWB/FW-Vorrede-4; NW «Epílogo» 2, eKGWB/NW-Epilog-2

81. Cf. FP III 38 [12], eKGWB/NF-1885,38[12].

82. Za III «El convaleciente», $\mathbb{S} 2$, eKGWB/Za-III-Genesende-2. 